\title{
Two-parameter Rigid Block Approach to Upper Bound Analysis of Equal Channel Angular Extrusion Through a Segal 20-die
}

\author{
Alexander Perig ${ }^{a *}$ \\ ${ }^{a}$ Department of Industrial Automation, Donbass State Engineering Academy, \\ Shkadinova Str., 72, Kramatorsk, Ukraine, 84313
}

Received: April 16, 2015; Revised: May 31, 2015

\begin{abstract}
This article deals with a phenomenological description of experimentally determined complex geometric shape of material dead zone during Equal Channel Angular Extrusion (ECAE) through a Segal $2 \theta$-die with a channel intersection angle of $2 \theta>0^{\circ}$ and $2 \theta<180^{\circ}$. Taking into account the complex dead zone geometry in a $2 \theta$-die, a two-parameter Rigid Block Method (RBM) approach to a two-parameter Upper Bound Method (UBM) has been introduced with Discontinuous Velocity Field (DVF) for planar flow of plastic incompressible continua. The two-parameter UBM has allowed us to derive the numerical estimations for such energy-power parameters of ECAE as punching pressure and accumulated plastic strain for $2 \theta$-dies. The obtained computational data have been compared with the one-parameter analytic UBM solution. Good agreement between the two computational results has been found.
\end{abstract}

Keywords: ECAE, upper bound method, rigid block method, discontinuous velocity field, dead zone, strain

\section{Introduction}

Severe Plastic Deformation (SPD) techniques have become the prominent processing technologies ${ }^{1-28}$ for the production of bulk ultra fine-grained materials with special physical and mechanical properties ${ }^{28-32}$, by material pressure forming methods ${ }^{25,26}$. The mechanics of metal flow during Equal Channel Angular Extrusion (ECAE) or Equal Channel Angular Pressing (ECAP) through the $2 \theta$-dies of simple Segal geometry attracts a lot of research contributions from different fields of theoretical ${ }^{1-28}$, experimental ${ }^{28-32}$ and industrial ${ }^{8,25,33}$ science. ECAE assumes one or several extrusion passes of a lubricated billet in a $2 \theta$-die of Segal geometry with two intersecting channels of equal cross-section in Figures 1-2. Materials' processing by ECAE results in the accumulation of large shear strains and grain refinement. The obtained materials show the combination of a very high strength and ductility.

Therefore, studies of ECAE mechanics through the $2 \theta$-dies of simple Segal geometry form an important branch of modern applied plasticity science.

There are several computational approaches to the phenomenological description of metal flow during ECAE. Many contributions have been focused on the introduction of slip line fields ${ }^{25,26}$, Upper Bound Method (UBM) with continuous trial velocity fields ${ }^{1-6,8-10,12-15,24,27}$, kinematically admissible analytical approaches ${ }^{11,28}$, FEM computational techniques ${ }^{2,8,9,11,17,18,23}$, Navier-Stokes equations ${ }^{16,20,21}$ etc.

Segal ${ }^{25,26}$ has grounded his analytic approach to ECAE metal flow with the introduction of slip line fields. Tóth et al. ${ }^{28}$ have proposed a novel analytic approach to ECAE copper

*e-mail: olexander.perig@gmail.com flow with the introduction of a flow line model. Milind \& Date ${ }^{11}$ have applied generalized analytical kinematic models for ECAE strain estimation.

The Upper Bound Method (UBM)-based analytical solutions of ECAE problems for metal workpiece flow through ECAE dies have been derived in works of Abrinia \& Mirnia ${ }^{1}$, Alkorta \& Sevillano ${ }^{2}$, Altan et al. ${ }^{3}$, Eivani \& Karimi Taheri ${ }^{4,5}$, Faraji et al. ${ }^{6}$, Laptev et al. ${ }^{7}$, Luri et al. ${ }^{8}$, Luri \& Luis ${ }^{9}$, Medeiros et al. ${ }^{10}$, Narooei \& Karimi Taheri ${ }^{12-14}$, Paydar et al. ${ }^{15}$, Perig \& Laptev ${ }^{19}$, Perigg ${ }^{22}$, Reihanian et al. ${ }^{24}$, Talebanpour \& Ebrahimi ${ }^{27}$ and others. Altan et al. ${ }^{3}$ have addressed the Upper Bound Method (UBM) with continuous trial velocity fields for description of metal ECAE motion through the Segal die. The main computational approach ${ }^{3}$ has been based on the use of a cylindrical coordinate system with the center of a symmetrical metal deformation zone, definition of a kinematically admissible velocity field for metal flow, evaluation of the only non-zero strain rate field component $d\left(\varepsilon_{r \theta}\right) / d t$, formulation of an equation for dissipated power balance and further minimization of the derived expression for dissipated plastic power by optimization parameter differentiation.

The numerical finite difference simulation of polymer ECAE flow through angular dies with different geometries has been developed in the works of Perig et al. ${ }^{16}$, Perig \& Golodenko ${ }^{20,21}$. Perig et al. ${ }^{16}$ have applied the Navier-Stokes equations in the curl transfer form for the numeric finite-difference description of viscous material flow through the following dies: (I) ECAE die with channel intersection angle $2 \theta=90^{\circ[16]}$, (II) S-shaped multiple angle die with movable inlet wall ${ }^{20}$, and (III) ECAE die with channel intersection angle $2 \theta=90^{\circ}$ and 
with parallel slants in the channel intersection zone, where the slant width is equal to the inlet and outlet channel widths ${ }^{21}$.

There are finite element method (FEM)-based approaches to metal flow during SPD $2,8,9,11,217,18,23$. The FEM-based numerical solutions of ECAE problems for metal workpiece flow have been derived in works of Alkorta \& Sevillano ${ }^{2}$, Luri et al. ${ }^{8}$, Luri \& Luis ${ }^{9}$, Milind \& Date ${ }^{11}$, Perig et al. ${ }^{17,18,23}$ and others.

The quantitative description of material structure fragmentation during ECAE requires the introduction of experimental techniques ${ }^{28-32}$. Berta et al..$^{29}$ outline comparable experimental ECAE data on the structure of the treated metal blanks at various channel angles $2 \theta=90^{\circ}$ and $2 \theta=120^{\circ[29]}$.

It is necessary to note that many analytical computational approaches ${ }^{1-6,8-10,12-15,24,27}$ initially determine the shape of the dead metal zone CED in an angular Segal 20-die (Figures 3-6).

Simple physical simulation experiments for analysis of ECAE flow through a non-rectangular Segal $2 \theta$-die in Figures 3-6 show the complex structure of the dead metal zone $C E D F$ (Figures 3-6), which has not been adequately addressed in previous known publications ${ }^{1-10,12-15,19,22,24,27,28}$.

Moreover, the two-parameter rigid block approach to the two-parameter UBM of metal flow during ECAE with trial Discontinuous Velocity Field (DVF) introduction and accounting for the complex geometry of dead zone $C E D F$ (Figures 3-6) for metal flow through a Segal $2 \theta$-die has not been addressed in proper way in previous known publications $^{1-10,12-15,19,22,24,27}$.

All previous research ${ }^{1-10,12-15,19,22,24,27}$ has not fully addressed the complex geometry of the dead metal zone

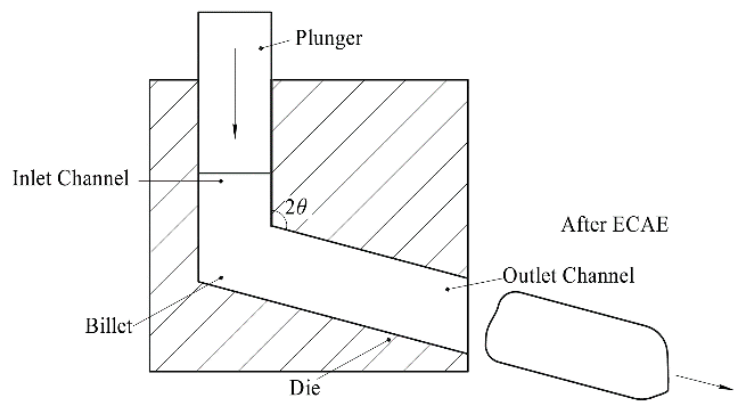

Figure 1. The principal scheme of ECAE billet processing through the $2 \theta$-die.

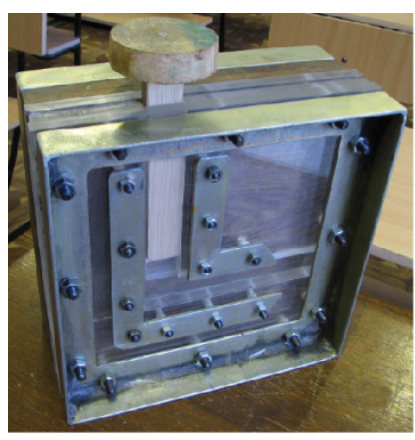

(a)

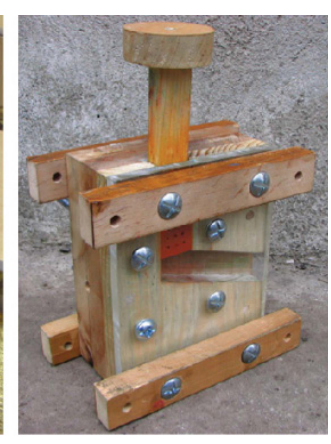

(b)
Figure 2. The principal scheme of ECAE billet processing through the $2 \theta$-die model with $2 \theta=90^{\circ}$ (a) and $2 \theta=105^{\circ}$ (b).

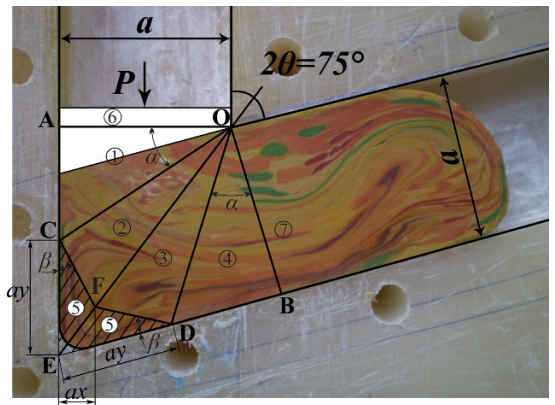

Figure 3. Physical model of the shape of the material dead zone $C E D F$ during ECAE through a Segal $2 \theta$-die with channel intersection angle $2 \theta=75^{\circ}$ after three ECAE passes via deformation route $\mathrm{C}$.

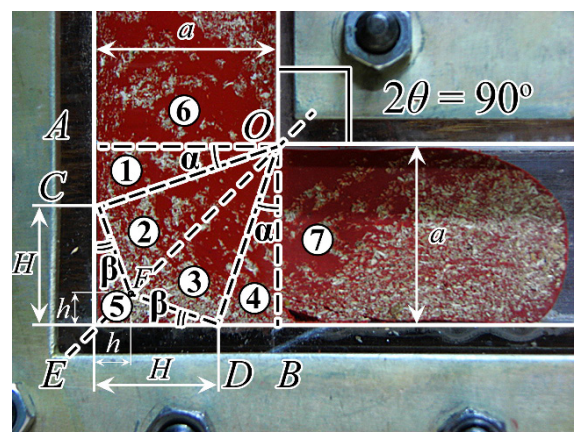

Figure 4. Physical model of the shape of material dead zone $C E D F$ during ECAE through a Segal $2 \theta$-die with channel intersection angle $2 \theta=90^{\circ}$.

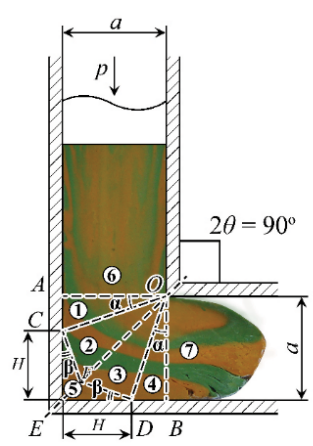

(a)

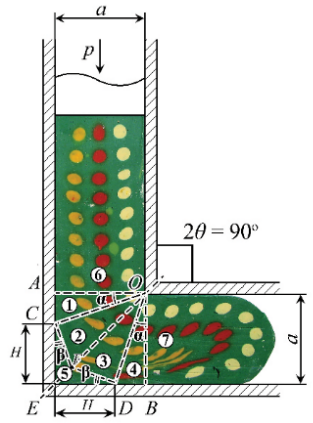

(c)

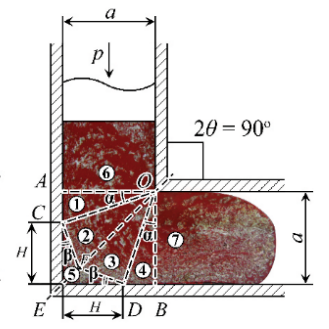

(b)

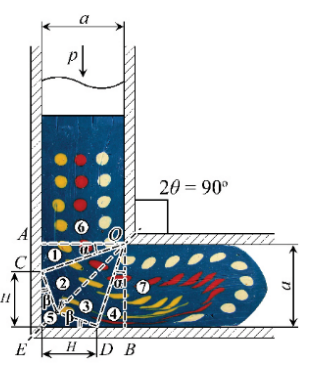

(d)
Figure 5. Physical models of the shape of material dead zone $C E D F$ during ECAE through a Segal die with channel intersection angle $2 \theta=90^{\circ}$ with an introduction of layered workpiece models (a), solid marker techniques (b), and initial circular gridlines (c, d). 


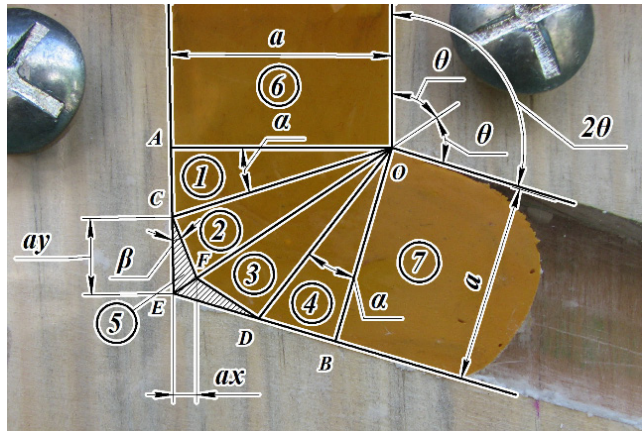

Figure 6. Physical model of the shape of material dead zone $C E D F$ during ECAE through a Segal $2 \theta$-die with channel intersection angle $2 \theta=105^{\circ}$.

$C E D F$ (Figures 3-6) nor the influence of complex dead zone geometry $C E D F$ (Figures 3-6) on the character of metal flow during workpiece ECAE through a Segal $2 \theta$-die applying a two-parameter UBM in the form of a two-parameter RBM with trial DVF. This insufficient analysis of energy-power parameters during ECAE with an introduction of the two-parameter UBM with DVF was the stimulus, which resulted in the research reported in the present article. This article is the first application of a two-parameter rigid block approach to a two-parameter UBM with DVF to workpiece $2 \mathrm{D}$ plastic flow through a Segal-geometry $2 \theta$-die.

The aim of the present research is the phenomenological Upper Bound Method-based description of metal workpiece plastic ECAE flow through a $2 \theta$ angular die of Segal geometry during ECAE accounting for the complex geometry of dead zone $C E D F$.

The subject of the present research is the plastic flow of metal workpiece model through the ECAE process with $2 \theta$ angular die of Segal geometry.

The object of the present research is the general definition of the character of the plastic flow of a metal workpiece model through a $2 \theta$ angular die of Segal geometry with respect to the complex dead zone geometry and ECAE process parameters.

The experimental novelty of the present article is the introduction of initial circular gridlines to study workpiece flow through the ECAE process with $2 \theta$ angular dies of Segal geometry, shown in Perig's derived experimental approaches in Figures 3-6.

The prime novelty of the present research is the first time application of the two-parameter rigid block method to the estimation of punching pressure and plastic shear during metal workpiece ECAE through $2 \theta$-die of Segal geometry, accounting for the complex geometry of dead zone $C E D F$ in Figures 3-6.

\section{Complex Dead Zone Geometry Influence on Material Flow During ECAE}

In order to verify the complex character of dead metal zone $C E D F$ (Figures 3-6) we will address to simple physical simulation experiments with plasticine (Figures 3-6) workpiece models flow through the physical models of Segal $2 \theta$-dies with channel angles $2 \theta=75^{\circ}$ (Figure 3), $2 \theta=90^{\circ}$ (Figures 2a, 4-5), and $2 \theta=105^{\circ}$ (Figures 2b, 6).

The first experimental approach to analyze the dead metal zone shape CEDF (Figures 3-6) has been grounded on the introduction of layered models (Figure 5a) for workpiece model flow through a Segal-geometry die. However it has been found that layered models define only a general shape of dead zone $C E D$ near the corner point $E$ without clarification of dead zone $C E D$ external contours in the inlet $A O E$ and outlet $B O E$ die channels in Figure 5a. So a second type of approach has been applied using a physical marker experimental method (Figures 4 and $5 \mathrm{~b}$ ), which provided us with general idea about external shape of dead zone $C E D F$.

It has been found that dead metal zone $C E D F$ (Figures 3-6) in the workpiece volume has the shape near to the trial computational shape in Figure 7a. Additional physical simulation experiments required addressing to the physical models with the initial circular gridlines (Figures 3 and 5c-d). In Figures 3-6 the physical workpiece models' flow goes within inlet channel $A O C$ from the punch level to deformation zone entrance line $A O$; then towards bisector line $E O$ and then in the outlet channel $B O E$ from $E O$ to $B O$. Using both solid markers (Figures 4, 5b), layered models (Figure 5a), and initial circular gridlines (Figures 3 and $5 c-d$ ) it has been found experimentally that in the $2 \theta$-die external corner $E$ the dead zone $C E D F$ of plastic material flow appears and has a quite complex geometrical shape with additional "bottleneck" $E F$ (Figures 3-6), i.e. with formation of additional break point $F$ along bisecting line $E O$ in the area of the cross point for two intersecting conditional lines $E O$ and $A B$ (Figures 3-6).

\section{Two-Parameter Upper Bound Analysis for a Segal 20-Die}

In accordance with observable results of physical simulation-based experiments in Figures 3-6 we assume the formation of a complex shape dead zone $C E D F$ with the appearance of the additional straight arch $E F$, which limits the "spreading" of the metal dead zone to the $C D F$ area in Figures 3-7. So the appearance of a symmetrical complex shape dead metal zone $C E D F$ has been shown in Figures 3-7.

The upper bound theorem equation according to the works $^{34,35}$ has the following form:

$\left(\frac{d E}{d t}\right)_{\text {Johnson-Kudo }}=\left(k \sum l_{i j} \Delta u_{i j}^{\prime}\right)_{\text {Johnson- Kudo }}+\left(\sum f_{k} l_{k} \Delta u_{\mathrm{k}}^{\prime}\right)_{\text {Johnson- Kudo }}$

where

$(\mathrm{d} E / \mathrm{d} t)_{\text {Johnson-Kudo }}$ is defined in Johnson \& $\mathrm{Kudo}^{34}$ and Kudo ${ }^{35}$ as "the total rate of energy dissipation in the system per unit thickness in the direction normal to the plane of flow"; multiplier $(\mathrm{k})_{\text {Johnson-Kudo }}$ is defined in Johnson \& Kudo ${ }^{34}$ and $\mathrm{Kudo}^{35}$ as "the shear stress";

$\left(l_{I J}\right)_{\text {Johnson-Kudo }}$ and $\left(\Delta u_{I J}^{\prime}\right)_{\text {Johnson-Kudo }}$ are defined in Johnson \& $\mathrm{Kudo}^{34}$ and $\mathrm{Kudo}^{35}$ as "the length of a straight boundary and the rate of relative slip between triangles " $i$ " and " $j$ " respectively";

$\left(f_{K}\right)_{\text {Johnson-Kudo }},\left(l_{K}\right)_{\text {Johnson-Kudo }}$ and $\left(\Delta u_{K}^{\prime}\right)_{\text {Johnson-Kudo }}$ with subscript $\mathrm{k}$ are defined in Johnson \& $\mathrm{Kudo}^{34}$ and Kudo ${ }^{35}$ as "the frictional resistance, the length of contact and the rate of relative slip between triangle $\mathrm{k}$ and the contacting tool surface" $" 34,35$ ). 
It has been shown that the dead zone $C E D F$ shape may be only symmetrical one with axis of symmetry $E F$, because possible asymmetry of dead zone $C E D F$ leads to a violation of workpiece material incompressibility for the rigid blocks division used in Figures 3-6, 7a. The 2D plane model of the metal workpiece during ECAE in $2 \theta$-die has been divided into 7 rigid triangular sections, as shown in Figures 3-6, 7a.

According to the two-parameter UBM (Figures 3-6, 7a, Tables 1-3) a trial velocity field (Figure 7b, Tables 1-3) has to be introduced.

For the analysis of the ECAE metal flow the trial velocity field for UBM can be continuous, discontinuous or mixed. In the present work the Discontinuous Velocity Field (DVF) for the two-parameter UBM has been used in Figure $7 \mathrm{~b}$ and in Tables 1-3. Derived experimental data have shown that it's better to describe the shape of the symmetrical dead zone $C E D F$ in Figures 3-6, 7a and in Tables 1-3 with two independent parameters $h=a \bullet x$ and $H=a \bullet y$. Here $a$ is the width of inlet $A O$ and outlet $B O 2 \theta$-die channels; $x$ is the relative horizontal length of "waist" or bottleneck and $y$ is the relative height of the dead zone in both entrance $A O E$ and outlet $B O E$ channels (Figures 3-6, 7a and Tables 1-3). The appearance of a symmetrical dead metal zone $C E D F$ in the shape of the twin rigid triangular block numbered 5 , which is adjacent to the $2 \theta$-die external angle $C E D$, locates in both inlet $A O E$ and outlet $E O B$ 2 $\theta$-die channels (Figures 3-6, 7a and Tables 1-3) and has the height $H=a \bullet y$ and length $h=a \cdot x$. We also will assume that metal ECAE through a Segal $2 \theta$-die with channel intersection angle $2 \theta>0^{\circ}$ and $2 \theta<180^{\circ}$ occurs with no back-pressure. Additionally we will assume that the constant plastic friction between the workpiece and $2 \theta$-die walls $A C$ and $D B$ is independent of the normal stress $\sigma_{N}$ and is acting only at inlet $l_{A C}$ and outlet $l_{D B}$ lengths (Figures 3-6, 7a and Tables 1-3).

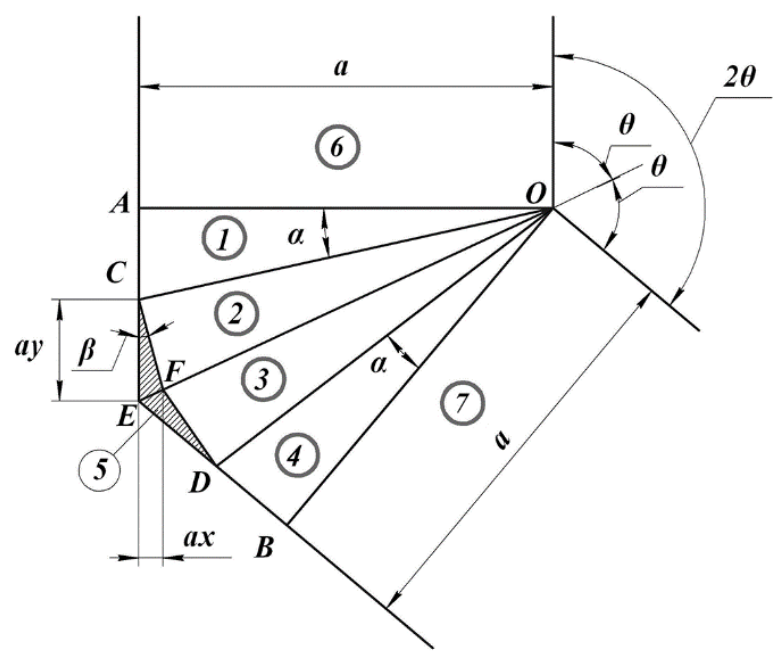

(a)
The friction stress $\tau_{F}$ we will define according to the Siebel (Tresca) friction law as $\tau_{F}=m \bullet k$, where $0.0 \leq m \leq 1.0$ is the plastic friction factor in the Siebel (Tresca) friction law and the shear strength of the extruded material $k=\sigma_{S} / 3^{0.5}$ is the plastic constant, i.e. $k$ is the maximum tangential stress for material with flow stress $\sigma_{S}$. We will calculate the relative punching pressure $p / 2 k$ (Figures $8 \mathrm{a}, \mathrm{c} ; 9 \mathrm{a}, \mathrm{c}$ ) at the entrance line $A O$. Corresponding to the partitioning scheme in Figures 3-6, 7a and in Tables 1-3 a velocity hodograph has been shown in Figure $7 \mathrm{~b}$. The extruded workpiece material we will assume as rigid-plastic with no strain-hardening. The plastic friction force has been assumed as independent of sliding velocity.

The balance of external and internal power of plastic deformation has been expressed by the following algebraic equation (Figures 3-9 and Tables 1-3):

$$
\begin{aligned}
& p \cdot a \cdot V_{1}=k \cdot \\
& \left(l_{1-2} \cdot\left[V_{1-2}\right]+l_{2-3} \cdot\left[V_{2-3}\right]+l_{3-4} \cdot\left[V_{3-4}\right]+l_{2-5} \cdot\left[V_{2-5}\right]+l_{3-5} \cdot\left[V_{3-5}\right]\right)+ \\
& +m k \cdot\left(l_{A C} \cdot V_{1}+l_{D B} \cdot V_{3}\right)
\end{aligned}
$$

where $p$ is an applied ECAE punching pressure through the $2 \theta$-die of Segal geometry (Figures 8a,c;9a,c);

$l_{I-J}$ are the lengths of common boundaries or join interfaces for rigid blocks $i$ and $j$ (Figures 3-6, 7a and Tables 1-3);

$l_{1-2}=l_{3-4}=C O$ (Figures 3-6, 7a and Tables 1-3);

$l_{2-3}=E O($ Figures 3-6, 7a and Tables 1-3);

$\mathrm{EF}=\frac{\mathrm{ax}}{\sin \theta}$ is the length of additional straight arch $E F$ in

Figures 3-6, 7a;

$l_{A C}=l_{D B}$ are the lengths of friction zones in Figures 3-6, 7a, where $A C=a(\cot \theta-y)$;

$\sin \alpha=\frac{\mathrm{AC}}{\mathrm{CO}}=\frac{\cot \theta-\mathrm{y}}{\sqrt{1+(\cot \theta-\mathrm{y})^{2}}}$ is the sine of angle $\alpha$ or the first algebraic equation for angle $\alpha$ determination in Figures 3-7;

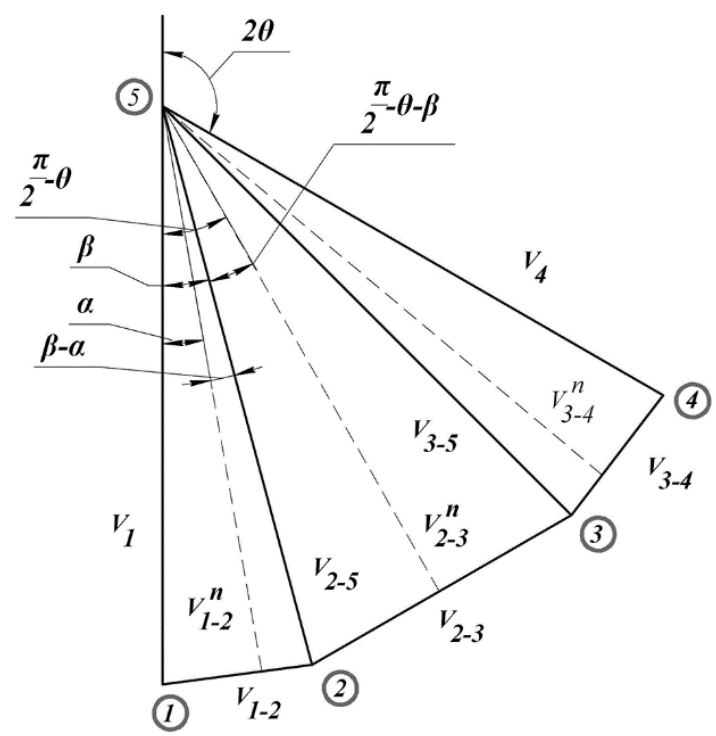

(b)

Figure 7. Scheme of ECAE 2 $\theta$-die of Segal geometry with non-zero friction $m \neq 0(a, b): a$ - rigid block two-parameter partitioning scheme; $\mathrm{b}$ - corresponding velocity hodograph for the two-parameter UBM model, where $2 \theta>0^{\circ}$ and $2 \theta<180^{\circ}$. 
Table 1. The lines of discontinuity and sliding velocities for ECAE $2 \theta$-die with $2 \theta>0^{\circ}$ and $2 \theta<180^{\circ}(x=h / a$ and $y=H / a)$ in Figures 3-7.

\begin{tabular}{lcc}
\hline Velocity discontinuity lines $i-j$ & $l_{i-j}$ & {$\left[V_{i-j}\right]$} \\
\hline $1-2$ & $\mathrm{a} \sqrt{1+(\cot \theta-\mathrm{y})^{2}}$ & $\frac{\mathrm{V}_{1} \mathrm{x} \sqrt{1+(\cot \theta-\mathrm{y})^{2}}}{\mathrm{y}(1-\mathrm{x})}$ \\
$2-3$ & $\frac{\mathrm{a}}{\sin \theta}(1-\mathrm{x})$ & $\frac{2 \mathrm{~V}_{1}}{\mathrm{y}(1-\mathrm{x})}(\mathrm{y} \cdot \cos \theta-\mathrm{x} \cdot(\cos \theta \cdot \cot \theta+\sin \theta))$ \\
$3-4$ & $\mathrm{a} \sqrt{1+(\cot \theta-\mathrm{y})^{2}}$ & $\frac{\mathrm{V}_{1} \mathrm{x} \sqrt{1+(\cot \theta-\mathrm{y})^{2}}}{\mathrm{y}(1-\mathrm{x})}$ \\
$2-5$ & $\mathrm{a} \sqrt{\mathrm{y}^{2}+\mathrm{x}^{2}\left(1+(\cot \theta)^{2}\right)-2 \mathrm{xy} \cdot \cot \theta}$ & $\frac{\mathrm{V}_{1} \sqrt{\mathrm{y}^{2}+\mathrm{x}^{2}\left(1+(\cot \theta)^{2}\right)-2 \mathrm{xy} \cdot \cot \theta}}{\mathrm{y}(1-\mathrm{x})}$ \\
$3-5$ & $\mathrm{a} \sqrt{\mathrm{y}^{2}+\mathrm{x}^{2}\left(1+(\cot \theta)^{2}\right)-2 \mathrm{xy} \cdot \cot \theta}$ & $\frac{\mathrm{V}_{1} \sqrt{\mathrm{y}^{2}+\mathrm{x}^{2}\left(1+(\cot \theta)^{2}\right)-2 \mathrm{xy} \cdot \cot \theta}}{\mathrm{y}(1-\mathrm{x})}$
\end{tabular}

Table 2. The lines of discontinuity and sliding velocities for ECAE $2 \theta$-die with $2 \theta>0^{\circ}$ and $2 \theta<180^{\circ}(x=h / a$ and $y=H / a)$ in Figures 3-7.

\begin{tabular}{cc}
\hline Velocity discontinuity lines $\mathbf{i}-\mathbf{j}$ & $\frac{V_{i-j}^{n}}{1-2}$ \\
\hline $2-3$ & $\frac{\mathrm{V}_{1}}{\sqrt{1+(\cot \theta-\mathrm{y})^{2}}}$ \\
$3-4$ & $\frac{\mathrm{V}_{1} \sin \theta}{(1-\mathrm{x})}$ \\
$2-5$ & $\frac{\mathrm{V}_{1}}{\sqrt{1+(\cot \theta-\mathrm{y})^{2}}}$ \\
$3-5$ & 0 \\
\hline
\end{tabular}

Table 3. The lines of discontinuity and sliding velocities for ECAE die with $2 \theta=90^{\circ}(x=h / a$ and $y=H / a)$ in Figures 4-5.

\begin{tabular}{|c|c|c|c|}
\hline $\begin{array}{c}\text { Velocity discontinuity } \\
\text { lines } i-j\end{array}$ & $l_{i-j}$ & {$\left[V_{i-j}\right]$} & $V_{i-j}^{n}$ \\
\hline $1-2$ & $a \sqrt{1+(1-y)^{2}}$ & $\frac{\mathrm{V}_{1} \cdot \mathrm{x} \sqrt{1+(1-\mathrm{y})^{2}}}{\mathrm{y} \cdot(1-\mathrm{x})}$ & $\frac{\mathrm{V}_{1}}{\sqrt{1+(1-\mathrm{y})^{2}}}$ \\
\hline $2-3$ & $\sqrt{2} \cdot a \cdot(1-x)$ & $\frac{\sqrt{2} \cdot V_{1} \cdot(y-2 x)}{y \cdot(1-x)}$ & $\frac{V_{1}}{\sqrt{2} \cdot(1-x)}$ \\
\hline $3-4$ & $a \sqrt{1+(1-y)^{2}}$ & $\frac{\mathrm{V}_{1} \cdot \mathrm{x} \sqrt{1+(1-\mathrm{y})^{2}}}{\mathrm{y} \cdot(1-\mathrm{x})}$ & $\frac{\mathrm{V}_{1}}{\sqrt{1+(1-\mathrm{y})^{2}}}$ \\
\hline $2-5$ & $a \sqrt{x^{2}+(y-x)^{2}} 10$ & $\frac{\mathrm{V}_{1} \cdot \sqrt{\mathrm{x}^{2}+(\mathrm{y}-\mathrm{x})^{2}}}{\mathrm{y} \cdot(1-\mathrm{x})}$ & 0 \\
\hline $3-5$ & $a \sqrt{x^{2}+(y-x)^{2}}$ & $\frac{V_{1} \cdot \sqrt{x^{2}+(y-x)^{2}}}{y \cdot(1-x)}$ & 0 \\
\hline
\end{tabular}


$\cos \alpha=\frac{\mathrm{AO}}{\mathrm{CO}}=\frac{1}{\sqrt{1+(\cot \theta-\mathrm{y})^{2}}}$ is the cosine of angle $\alpha$ or the second algebraic equation for angle $\alpha$ determination in Figures 3-7;

$\tan \alpha=\frac{\mathrm{AC}}{\mathrm{AO}}=\cot \theta-\mathrm{y}$ is the tangent of angle $\alpha$ or the third algebraic equation for angle $\alpha$ determination in Figures 3-7;

$\sin \beta=\frac{E F}{C E} \sin \theta=\frac{x}{\sqrt{y^{2}+x^{2}\left(1+(\cot \theta)^{2}\right)-2 x y \cdot \cot \theta}}$ is the sine of angle $\beta$ or the first algebraic equation for angle $\beta$ determination in Figures 3-7; $\cos \beta=\frac{\mathrm{CK}}{\mathrm{CE}}=\frac{(\mathrm{y}-\mathrm{x} \cdot \cot \theta)}{\sqrt{\mathrm{y}^{2}+\mathrm{x}^{2}\left(1+(\cot \theta)^{2}\right)-2 \mathrm{xy} \cdot \cot \theta}}$ is the cosine of angle $\beta$ or the second algebraic equation for angle $\beta$ determination in Figures 3-7; $\tan \beta=\frac{\mathrm{KE}}{\mathrm{CK}}=\frac{\mathrm{x}}{(\mathrm{y}-\mathrm{x} \cdot \cot \theta)}$ is the tangent of angle $\beta$ or the third algebraic equation for angle $\beta$ determination in Figures 3-7; $\left[V_{I-J}\right]$ are the velocities of relative sliding for these blocks $i$ and $j$ (Figures 3-6, 7a and Tables $1-3) ; i, j=1,2,3,4,5 ; V_{1}$ and $V_{3}$ are material velocities in the inlet $A O E$ and outlet $O E B 2 \theta$-die channels respectively (Figures 3-7), and due to the ECAE process symmetry requirement we have $V_{1}=V_{3}$.

The terms in Equation 2 have been expressed as the functions of punching velocity $V_{1}$ and the relative dimensions of the metal dead zone CEDF in Figures 3-7: $x=h / a$ and $y=H / a$. After substitution of obtained relationships in Equation 2 and algebraic transformation, the following elementary formula for calculation of relative punching pressure $p / 2 k$ has been derived and shown in Figures 8a,c;9a,c for two-parameter UBM (०००):

$\frac{p}{2 k}=\left(\frac{(1+x)\left(\mathrm{y}^{2}+x\left(1+(\cot \theta)^{2}\right)\right)-4 x y \cdot \cot \theta}{\mathrm{y}(1-\mathrm{x})}\right)+$

$\cot \theta-\left(\frac{x}{y}\right)\left(1+(\cot \theta)^{2}\right)+m(\cot \theta-y)$

For ECAE die with $2 \theta=90^{\circ}$ (Figures 4-5) Equation 3 yields

$$
\left(\frac{p}{2 k}\right)_{2 \theta=90^{\circ}}=\frac{\left(4 x^{2}+(1+x) y^{2}-5 x y+y\right)}{y(1-x)}+m(1-y)
$$

According to the UBM the best approximation of the real $p / 2 k$ corresponds to the minimum of expression (3), i.e. requires the solution of the following system of equations:

$$
\left\{\begin{array}{l}
\frac{\partial}{\partial \mathrm{x}}\left(\frac{p}{2 k}\right)=0 \\
\frac{\partial}{\partial y}\left(\frac{p}{2 k}\right)=0 .
\end{array}\right.
$$

The analysis of (5) shows that the minimum of the function $(p / 2 k)$ for ECAE punching pressure during metal workpiece extrusion through the Segal $2 \theta$-die with a channel intersection angle of $2 \theta>0^{\circ}$ and $2 \theta<180^{\circ}$ will occur for the real numerical solutions of the following transcendental system of algebraic equations:

$$
\left\{\begin{array}{l}
x \cdot(2-x) \cdot\left(1+(\cot \theta)^{2}\right)+y^{2}-2 \cdot y \cdot \cot \theta=0 \\
y^{2} \cdot(1+x)-2 \cdot x^{2} \cdot\left(1+(\cot \theta)^{2}\right)-m \cdot y^{2} \cdot(1-x)=0 .
\end{array}\right.
$$

For ECAE die with $2 \theta=90^{\circ}$ (Figures 4-5) systems (6) transforms into

$$
\left\{\begin{array}{l}
\left(y^{*}\right)^{2}-2\left(x^{*}\right)^{2}+4 x^{*}-2 y^{*}=0 \\
\left(y^{*}\right)^{2}\left(x^{*}(1+m)+(1-m)\right)-4\left(x^{*}\right)^{2}=0
\end{array}\right.
$$

Using the Equations 3 and 6 we may estimate the dimensions $H$ and $h$ of dead zone $C E D F$ in Figures 3-6, 7a and the value $p / 2 k$ (Figures $8 \mathrm{a}, \mathrm{c} ; 9 \mathrm{a}, \mathrm{c}$ ) of the ECAE punching pressure. In the present work the system (6) has been solved numerically in the case of fixed values for friction factor $m$.

ECAE is an SPD technique for grain refinement. Therefore the estimation of resulting plastic ECAE shear is also important. The total ECAE shear $\gamma_{S}$ is the sum of the shears on the discontinuity lines $C O, F O$ and $D O$ in Figures 3-6, 7a, i.e.

$\gamma_{\mathrm{S}}=\gamma_{1-2}+\gamma_{2-3}+\gamma_{3-4}$

It has been known that

$\gamma_{i-j}=\frac{\left[V_{\mathrm{i}-j}\right]}{V_{i-j}^{n}}$

where $V_{I-J}^{N}$ is a velocity component orthogonal to a discontinuity line $l_{I-J}$ (Figure $7 \mathrm{~b}$ ).

Using Equation 8 and the hodograph in Figure $7 \mathrm{~b}$ we have obtained the following relationship for the total plastic shear during ECAE through a Segal $2 \theta$-die with channel intersection angle of $2 \theta>0^{\circ}$ and $2 \theta<180^{\circ}$ (Figures $8 \mathrm{~b}, \mathrm{~d} ; 9 \mathrm{~b}, \mathrm{~d}$ ):

$$
\gamma_{S}=\left(\frac{2 \cdot x \cdot\left(1+(\cot \theta-y)^{2}\right)}{(y \cdot(1-x))}\right)+2 \cdot \cot \theta-\left(\frac{2 \cdot x}{\left(y \cdot \sin ^{2} \theta\right)}\right)
$$

For ECAE die with $2 \theta=90^{\circ}$ (Figures 4-5) Equation 10 yields

$$
\gamma_{S}=\frac{2 \cdot x \cdot\left(1+(1-y)^{2}\right)}{y \cdot(1-x)}+\frac{2 \cdot(y-2 x)}{y}
$$

\section{Comparison with Published Theoretical Results}

The obtained results (2)-(11), derived with two-parameter UBM introduction ( $\circ \circ)$ have been compared with upper bound solution by Perig ${ }^{22}$ (-) for relative punching pressure $(p / 2 k)_{\text {Perig }}$ and summary shear $\gamma_{\text {Perig }}{ }^{22}$ for $2 \theta=75^{\circ}$ (Figures $8 \mathrm{a}, \mathrm{b}$ ), $2 \theta=105^{\circ}$ (Figures $8 \mathrm{c}, \mathrm{d}$ ), $2 \theta=120^{\circ}$ (Figures 9a,b), and $2 \theta=135^{\circ}$ (Figures 9c,d):

$$
\left\{\begin{array}{l}
\left(\frac{p}{2 k}\right)_{\text {one-param }}=\left(\frac{\left(1+\tilde{x} \cdot \tan (\theta)+(\cot \theta-\tilde{x})^{2}\right)}{(\tan (\theta)+(\cot (\theta)-\tilde{x}))}\right)+m \cdot(\cot (\theta)-\tilde{x}) \\
\left(\gamma_{S}\right)_{\text {one-param }}=\left(\frac{2 \cdot\left(1+(\cot (\theta)-\tilde{x})^{2}\right)}{(\tan (\theta)+(\cot (\theta)-\tilde{x}))}\right) \\
\tilde{x}=\left(\frac{\left[(1+m)\left(1+\tan ^{2}(\theta)\right)-\tan (\theta) \cdot \sqrt{2 \cdot(1+m) \cdot\left(1+\tan ^{2}(\theta)\right)}\right]}{[(1+m) \cdot \tan (\theta)]}\right] .
\end{array}\right.
$$


The results of the comparison have been presented in Figures 8-9 and in Table 4. Good agreement, especially for plastic shear $\gamma_{\mathrm{S}}$, has been found, where $\delta$ is the averaged relative divergence of the computational results, which was evaluated by the formula:

$\delta=\left\langle\frac{1}{2}\left(\left|\frac{\left(R_{1 U B M}-R_{2 U B M}\right)}{R_{1 U B M}}\right|+\left|\frac{\left(R_{1 U B M}-R_{2 U B M}\right)}{R_{2 U B M}}\right|\right) \cdot 100 \%\right\rangle(13)$

where $R_{2 U B M}$ and $R_{\text {IUBM }}$ and in (13) are the values obtained by upper bound method formulae for two-parameter UBM (3), (6), (10) ( $\left.R_{2 U B M}, \circ \circ \circ\right)$ and one-parameter UBM (12) $\left(R_{1 U B M},-\right)$ respectively (Table 4$)$.

The numerical plots for ECAE punching pressure $p / 2 k$, derived with Equations 3 and 6 for two-parameter UBM

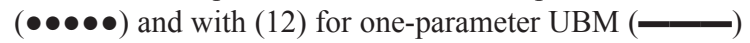

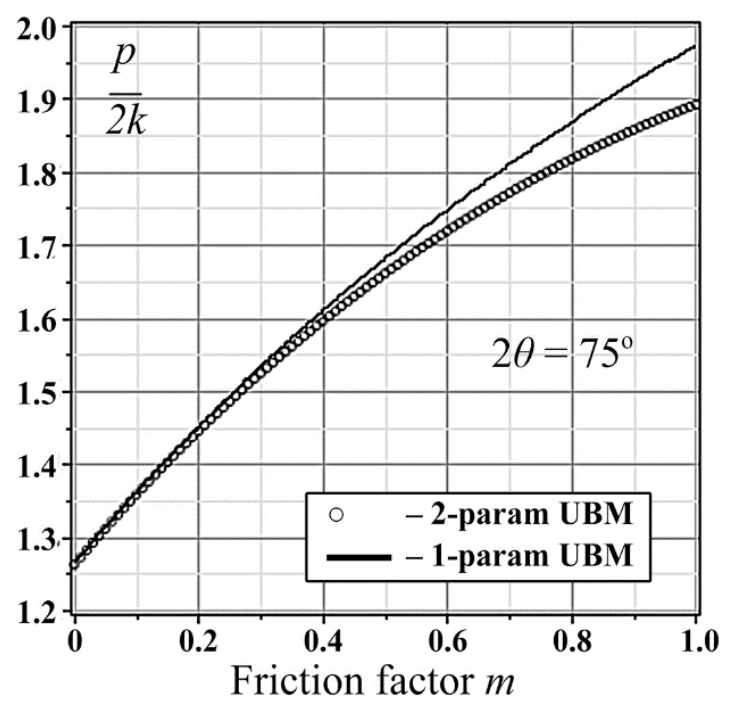

(a)

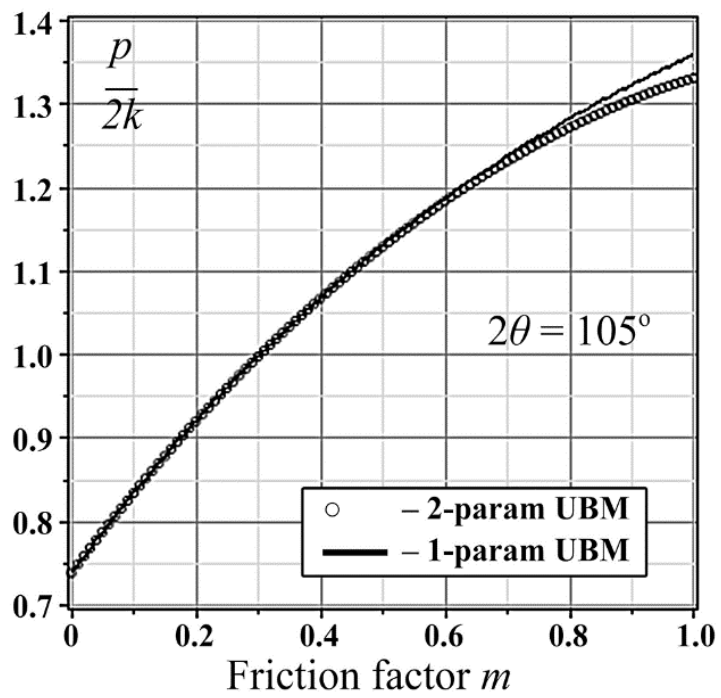

(c) are shown in Figures 8a,c;9a,c. The relative discrepancy for two-way ECAE punching pressure UBM estimation in Figures 8a,c;9a,c is shown in Table 4. The comparative plots for ECAE accumulated plastic shear $\gamma_{S}$, derived with

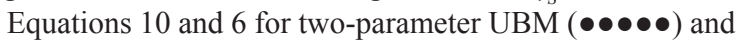
with (12) for one-parameter UBM (_-) are outlined in Figures $8 b, d ; 9 b, d$. The relative discrepancy for two-way ECAE plastic shear UBM estimation in Figures 8b,d;9b,d is also shown in Table 4.

The value of the accumulated plastic shear (Figures 8b,d;9b,d) decreases with increasing friction factor. This general trend is assumed to be caused by additional metal sticking to the die walls during ECAE without lubrication. The area of dead metal zone $C E D F$ increases with friction growth. In such cases with maximum friction takes place the destruction of

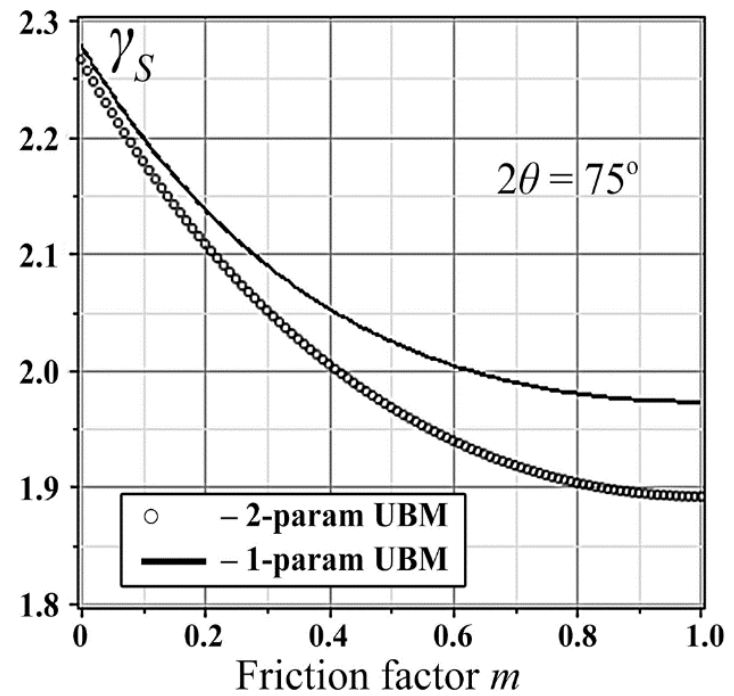

(b)

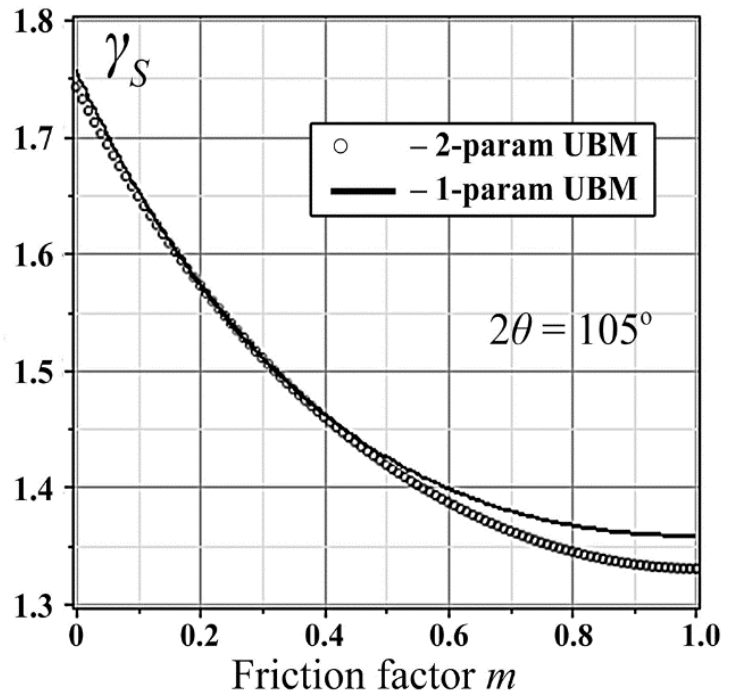

(d)

Figure 8. Computational dependencies of ECAE punching pressure $p / 2 k(\mathrm{a}, \mathrm{c})$ and the total plastic shear $\gamma_{S}(\mathrm{~b}, \mathrm{~d})$ with respect to friction factor $m$ for the ECAE Segal $2 \theta$-dies with $2 \theta=75^{\circ}(\mathrm{a}, \mathrm{b})$ and $2 \theta=105^{\circ}(\mathrm{c}, \mathrm{d})$, derived by two-parameter UBM (०००), and one-parameter $\operatorname{UBM}(-)$. 
workpiece surface with formation of additional wrinkles and burrs at workpiece surface. These defects, together with the large dead zone and growing metal sticking violate the dynamics of macroscopic rotation within volume of worked material, which determines the value of accumulated plastic shear during ECAE. This causes above mentioned decrease of accumulated plastic shear (Figures 8b,d;9b,d) with the increase of the friction factor during ECAE through a Segal $2 \theta$-die with $2 \theta>0^{\circ}$ and $2 \theta<180^{\circ}$.

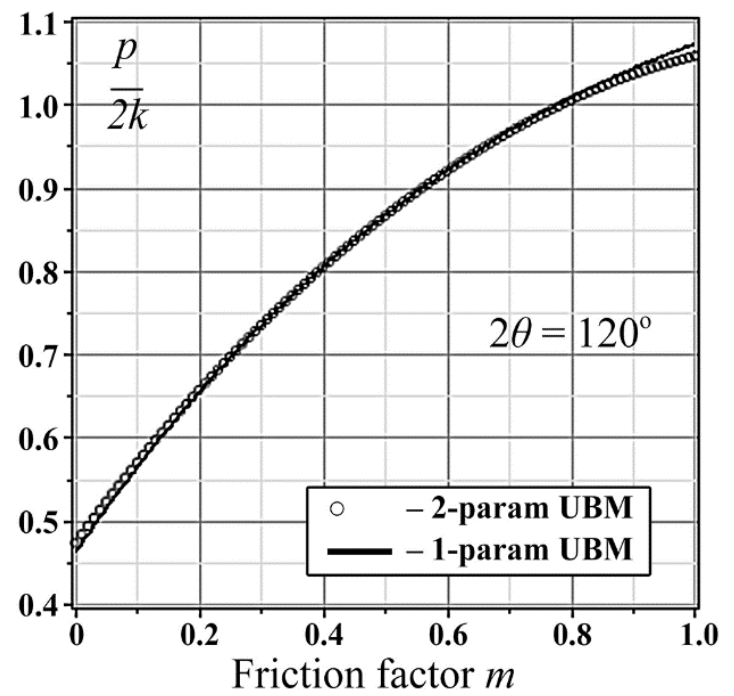

(a)

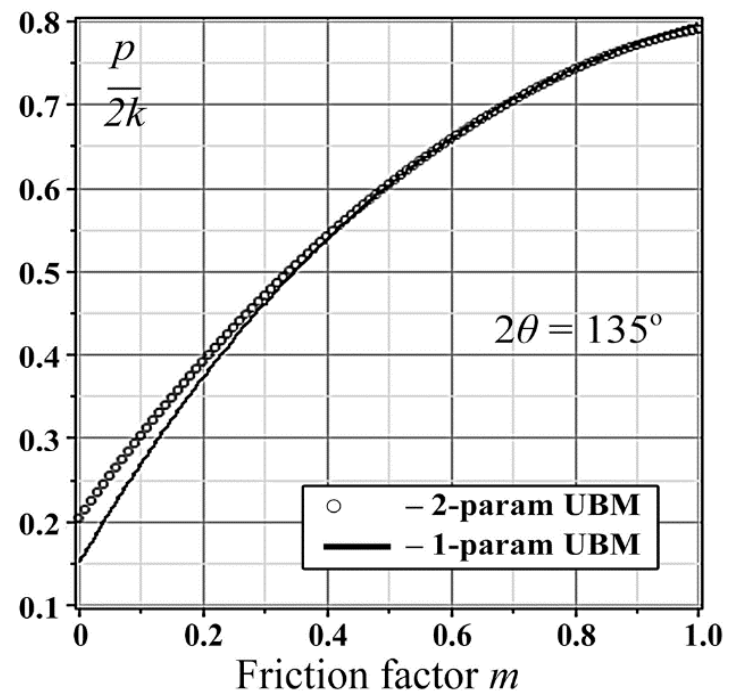

(c)

\section{Comparison with Published Experimental Results}

The results of the comparison of obtained two-parameter UBM values (3)-(4), (6) with published experimental data ${ }^{30,34}$ for ECAE punching pressure $p / 2 k$ are shown in Figure 10, where ECAE die angle is $2 \theta=90^{\circ}$ :

$\bullet \bullet \bullet \bullet \bullet$ - two-parameter UBM $p / 2 k$ results, estimated accordingly to (3)-(4), (6);

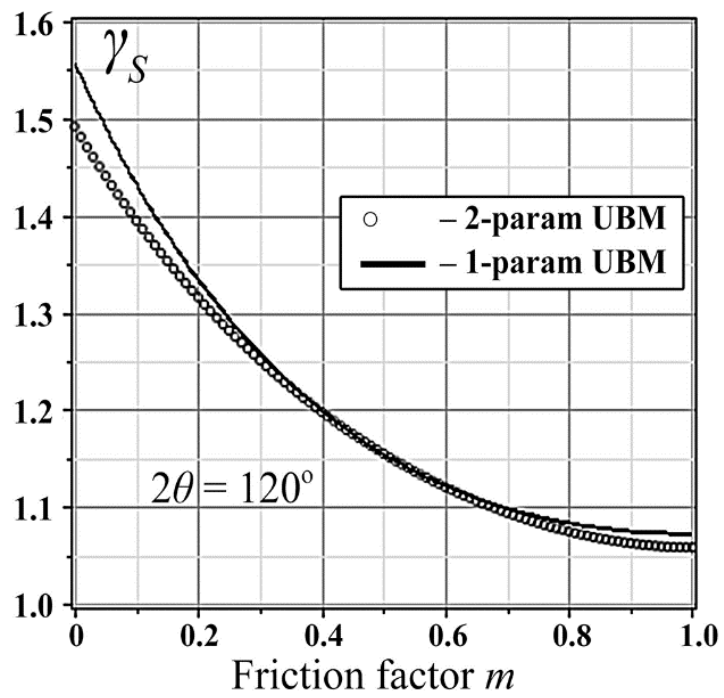

(b)

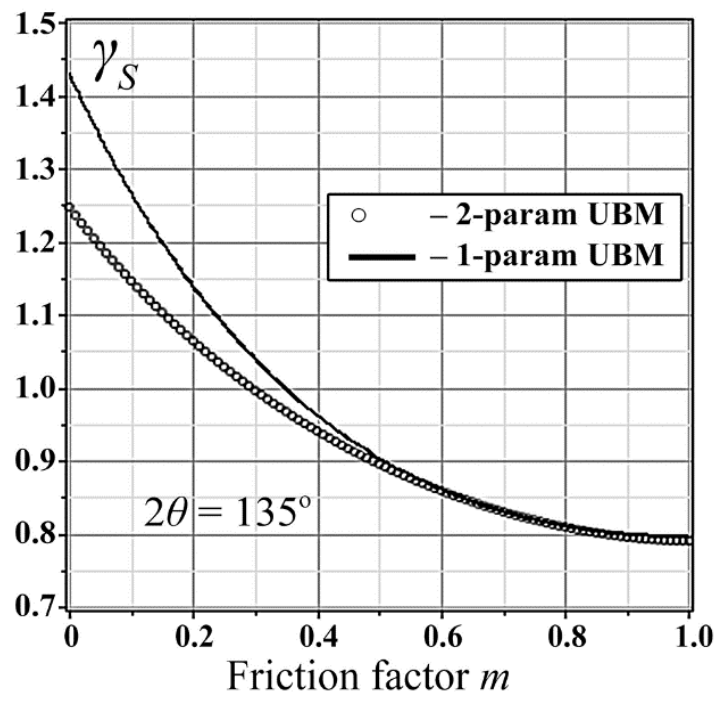

(d)

Figure 9. Computational dependencies of ECAE punching pressure $p / 2 k(\mathrm{a}, \mathrm{c})$ and the total plastic shear $\gamma_{S}(b, d)$ with respect to friction factor $m$ for the ECAE Segal $2 \theta$-dies with $2 \theta=120^{\circ}(\mathrm{a}, \mathrm{b})$ and $2 \theta=135^{\circ}(c, d)$, derived by two-parameter UBM (o००), and one-parameter $\operatorname{UBM}(-)$.

Table 4. Comparison of upper bound-estimated computational results for ECAE punching pressure $p / 2 k$ and total accumulated plastic strain $\gamma_{\mathrm{S}}$ derived with the introduction of two-way UBM techniques for Segal $2 \theta$-dies.

\begin{tabular}{cccccc}
\hline $\boldsymbol{\delta}$ & $2 \theta=75^{\circ}$ & $2 \theta=90^{\circ}$ & $2 \theta=105^{\circ}$ & $2 \theta=120^{\circ}$ & $2 \theta=135^{\circ}$ \\
\hline 2-param UBM vs. & $\delta(p)=2.852 \%$ & $\delta(p)=3.012 \%$ & $\delta(p)=1.233 \%$ & $\delta(p)=1.568 \%$ & $\delta(p)=17.849 \%$ \\
1-param UBM & $\delta\left(\gamma_{S}\right)=3.426 \%$ & $\delta\left(\gamma_{S}\right)=3.012 \%$ & $\delta\left(\gamma_{S}\right)=1.434 \%$ & $\delta\left(\gamma_{S}\right)=2.647 \%$ & $\delta\left(\gamma_{S}\right)=8.496 \%$ \\
\hline
\end{tabular}




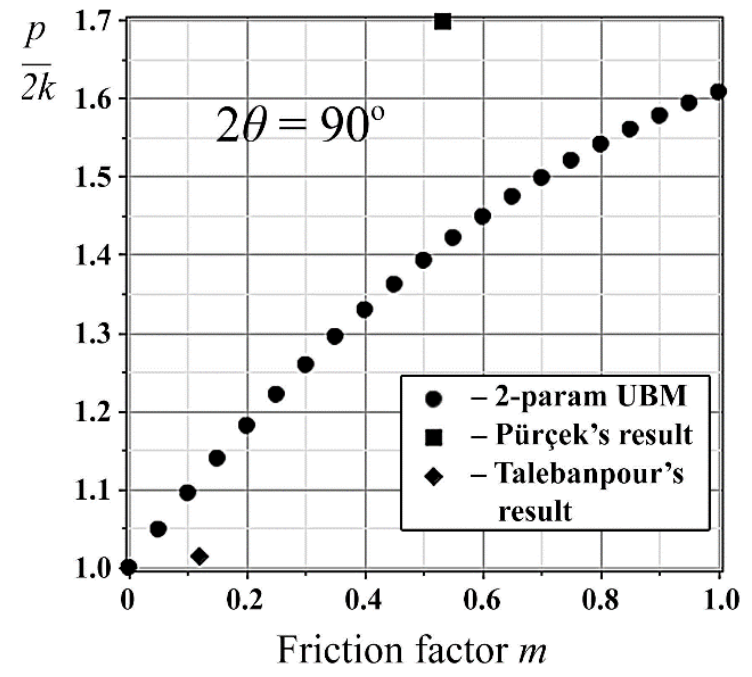

Figure 10. Comparison of theoretical results for relative punching pressure $p / 2 k$ derived with two-parameter UBM for non-hardening metal flow through a Segal die with channel intersection angle $2 \theta=90^{\circ}$ with published experimental results for relative punching pressure $p / 2 k$ : $\bullet \bullet \bullet \bullet-$ computational two-parameter UBM result calculated according to (3)-(4), and (6); - - G. Pürçek experiment (results divergence is $\left.\delta_{\mathrm{G} \text {. Püreek }}(p / 2 k)=16.48 \%{ }^{[32]}\right) ;-\mathrm{B}$. Talebanpour experiment (results divergence is $\delta_{\text {B. Talebanpour }}(p / 2 k)=9.76^{\circ[27]}$ ).

- - G. Pürçek experiment in Figure 10 (Pürçek's workpiece material was $\mathrm{Zn}-\mathrm{Al}-12$, Pürçek's punching temperature was $t=75 \pm 3{ }^{\circ} \mathrm{C}$, Pürçek's lubrication was molybdenum disulphide, Pürçek's maximum punching pressure was $p_{\text {MAX }}=496 \mathrm{MPa}$, Pürçek's yield stress was $\sigma_{S}=253 \mathrm{MPa}$, results divergence between UBM (3)-(4), (6) and Pürçek's experimental results in Pürçek ${ }^{32}$ is $\delta_{\text {G. Pürçek }}(p / 2 k)=16.48 \%$ as is shown in Figure 10 as $\mathbf{a}$ );

- B. Talebanpour experiment in Figure 10 (Talebanpour's workpiece material was commercially pure Aluminum, Talebanpour's punching temperature was $t=20^{\circ} \mathrm{C}$, Talebanpour's lubrication was mineral oil, Talebanpour's maximum punching pressure was $p_{M A X}=140 \mathrm{MPa}$, Talebanpour's yield stress was $k=69 \mathrm{MPa}$, results divergence between UBM (3)-(4), (6) and Talebanpour's experimental ECAE punching pressure results in Talebanpour \& Ebrahimi ${ }^{27}$ is $\delta_{\text {B. Talebanpour }}(p / 2 k)=9.76 \%$ as is shown in Figure 10 as ).

So good agreement of proposed two-parameter UBM approach with published experimental results has been obtained for an ECAE die with channel intersection angle $2 \theta=90^{\circ}$.

\section{Conclusions}

I. Physical simulation results for ECAE material flow through a Segal $2 \theta$-die with a channel intersection angle of $2 \theta>0^{\circ}$ and $2 \theta<180^{\circ}$ underline the complex geometry of dead zone for metal plastic flow. This experimentally determined fact was the stimulus resulting in the introduction of the two-parameter UBM to the metal ECAE problem for metal workpiece forcing through Segal $2 \theta$-die with channel intersection angle of $2 \theta>0^{\circ}$ and $2 \theta<180^{\circ}$.

II. The application of the two-parameter upper bound method (UBM) in the form of two-parameter rigid block method (RBM) with trial discontinuous velocity field (DVF) to the analysis of ECAE through a Segal $2 \theta$-die with $2 \theta>0^{\circ}$ and $2 \theta<180^{\circ}$ correctly describes the essential geometrical features for this SPD process, such as the appearance of a dead zone (DZ) and its increase as a function of external friction $m$.

III. Also the increase of ECAE punching pressure $p / 2 k$ and decrease of total plastic shear $\gamma_{\mathrm{S}}$, resulting from an increase in friction $m$ is well predicted with two-way ECAE parameter computations. The two-parameter upper bound (UBM) results based on a discontinuous velocity field (DVF) are in good agreement with the one-parameter upper bound solution results and published experimental results of Pürçek ${ }^{32}$ and Talebanpour \& Ebrahimi ${ }^{27}$.

IV. The proposed two-parameter upper bound approach can be applied to further analysis of metal workpieces ECAE flow through $2 \theta$-dies with external and internal radii in the channel intersection zone as well as for the dies for equal channel multiple angular extrusion, where angular dies have additional pairs of intersecting channels.

\section{Nomenclature}

- SPD is Severe Plastic Deformation;

- ECAE is Equal Channel Angular Extrusion;

- RBM is Rigid Block Method;

- UBM is Upper Bound Method;

- one-parameter UBM assumes dead zone shape in the form of isosceles triangle CED without additional bottleneck EF;

- two-parameter UBM assumes dead zone shape CEDF in the form of two adjacent triangles CEF \& DEF with formation of additional bottleneck EF;

- DVF is Discontinuous Velocity Field;

- DZ is Dead Zone;

- $a$ is the channel width of the ECAE die, [m];

- $2 \theta$ is the channel intersection angle of the ECAE die, [deg];

- The $2 \theta$-die is the angular die AEO-BEO with channel intersection angle $0^{\circ}<2 \theta<180^{\circ}$;

- The 2 $\theta$-die of Segal geometry is the angular die AEO - BEO with channel intersection angle $0^{\circ}<2 \theta<180^{\circ}$ without external and internal radii in channel intersection zone;

- $h=a x$ is the horizontal length of the dead zone $C E D F$, i.e. the horizontal projection of bottleneck EF, [m];

- $x=h / a$ is the relative dimensionless horizontal length of the dead zone $C E D F$, i.e. the first independent parameter for two-parameter UBM;

- $H=y a$ is the vertical length of the dead zone $C E D F$ within inlet die channel AEO, i.e. the relative height of the dead zone $C E D F,[\mathrm{~m}]$; 
- $y=H / a$ is the relative dimensionless vertical length of the dead zone $C E D F$ within inlet die channel AEO, i.e. the second independent parameter for twoparameter UBM;

- $i, j=1,2,3,4,5$;

- $\alpha=\alpha(x, y)$ and $\beta=\beta(x, y)$ are the angular coordinates, determining the area and the shape of the dead zone $C E D F,[\operatorname{deg}]$;

- $p$ is the Perig-derived ECAE punching pressure, obtained by the upper bound (UBM) theory with rigid blocks introduction, $[\mathrm{Pa}]$;

- $\sigma_{s}$ is the flow stress of the workpiece material, $[\mathrm{Pa}]$;

- $k$ is the plastic constant of the workpiece material, $[\mathrm{Pa}]$, where $\mathrm{k}=\sigma_{\mathrm{S}} / \sqrt{3}$ (in this case we assume the $2 \mathrm{D}$ plastic flow of the workpiece material, where the workpiece inlet and outlet die channels have rectangular cross sections);

- $p / 2 k$ is the dimensionless (relative) Perig-derived ECAE punching pressure, obtained by the upper bound (UBM) theory with rigid blocks introduction;

- $m$ is the dimensionless plastic friction factor in the Siebel (Tresca) friction law, where $0 \leq m \leq 1$;

\section{References}

1. Abrinia $\mathrm{K}$ and Mirnia MJ. A new generalized upper-bound solution for the ECAE process. International Journal of Advanced Manufacturing Technology. 2010; 46(1-4):411-421. http://dx.doi.org/10.1007/s00170-009-2103-y.

2. Alkorta J and Sevillano JG. A comparison of FEM and upperbound type analysis of equal-channel angular pressing (ECAP). Journal of Materials Processing Technology. 2003; 141(3):313318. http://dx.doi.org/10.1016/S0924-0136(03)00282-6.

3. Altan BS, Purcek G and Miskioglu I. An upper-bound analysis for equal-channel angular extrusion. Journal of Materials Processing Technology. 2005; 168(1):137-146. http://dx.doi. org/10.1016/j.jmatprotec.2004.11.010.

4. Eivani AR and Karimi Taheri A. An upper bound solution of ECAE process with outer curved corner. Journal of Materials Processing Technology. 2007; 182(1-3):555-563. http://dx.doi. org/10.1016/j.jmatprotec.2006.09.021.

5. Eivani AR and Karimi Taheri A. The effect of dead metal zone formation on strain and extrusion force during equal channel angular extrusion. Computational Materials Science. 2008; 42(1):14-20. http://dx.doi.org/10.1016/j.commatsci.2007.06.001.

6. Faraji G, Abrinia K, Mashhadi M and Hamdi M. An upperbound analysis for frictionless TCAP process. Archive of Applied Mechanics. 2013; 83(4):483-493. http://dx.doi.org/10.1007/ s00419-012-0697-2.

7. Laptev AM, Perig AV and Vyal OY. Analysis of equal channel angular extrusion by upper bound method and rigid blocks model. Materials Research. 2014; 17(2):359-366. http://dx.doi. org/10.1590/S1516-14392013005000187.

8. Luri R, Luis CJ, León J and Sebastián MA. A new configuration for equal channel angular extrusion dies. Journal of Manufacturing Science and Engineering-Transactions of the ASME. 2006; 128(4):860-865. http://dx.doi.org/10.1115/1.2194555.
- $l_{A C}=l_{D B}$ are the lengths of friction zones;

- $V_{1}$ is the workpiece material velocity in the inlet channel of the ECAE die, $[\mathrm{m} / \mathrm{s}]$;

- $V_{3}$ is the workpiece material velocity in the outlet channel of the ECAE die, $[\mathrm{m} / \mathrm{s}]$;

- $l_{i-j}$ are the lengths of common boundaries or interface joints for rigid blocks $i$ and $j$ within the rigid blocks partitioning scheme;

- $\left[V_{i-j}\right]$ are the relative sliding velocities for blocks $i$ and $j,[\mathrm{~m} / \mathrm{s}]$;

- $V_{i-j}^{n}$ is a velocity component orthogonal to a discontinuity line $l_{i-j},[\mathrm{~m} / \mathrm{s}]$;

- $\gamma_{i-j}=\left[V_{i-j}\right] / V_{i-j}^{n}$ is the dimensionless value of plastic shear at the inclined discontinuity line;

- $\gamma_{s}$ is the Perig-derived dimensionless value of total accumulated ECAE plastic shear, obtained by the upper bound (UBM) theory with rigid blocks introduction;

- $\delta$ is the relative dimensionless divergence (disagreement) of results, [\%].

9. Luri R and Luis CJ. Study of the ECAE process by the upper bound method considering the correct die design. Mechanics of Materials. 2008; 40(8):617-628. http://dx.doi.org/10.1016/j. mechmat.2008.02.003.

10. Medeiros N, Moreira LP, Bressan JD, Lins JFC and Gouvêa JP. Sensitivity analysis of the ECAE process via $2 \mathrm{k}$ experiments design. Matéria. 2010, 15(2):208-217. http://dx.doi.org/10.1590/ S1517-70762010000200018.

11. Milind TR and Date PP. Analytical and finite element modeling of strain generated in equal channel angular extrusion. International Journal of Mechanical Sciences. 2012; 56(1):26-34. http:// dx.doi.org/10.1016/j.ijmecsci.2011.12.002.

12. Narooei $\mathrm{K}$ and Karimi Taheri A. A new model for prediction the strain field and extrusion pressure in ECAE process of circular cross section. Applied Mathematical Modelling. 2010; 34(7):1901-1917. http://dx.doi.org/10.1016/j.apm.2009.10.008.

13. Narooei $\mathrm{K}$ and Karimi Taheri A. Strain field and extrusion load in ECAE process of bi-metal circular cross section. Applied Mathematical Modelling. 2012; 36(5):2128-2141. http://dx.doi. org/10.1016/j.apm.2011.08.008.

14. Narooei K and Karimi Taheri A. Using of Bezier formulation for calculation of streamline, strain distribution and extrusion load in rectangular cross section of ECAE process. International Journal of Computational Methods. 2013; 10(03):1350005. http://dx.doi.org/10.1142/S0219876213500059.

15. Paydar MH, Reihanian M, Ebrahimi R, Dean TA and Moshksar MM. An upper-bound approach for equal channel angular extrusion with circular cross-section. Journal of Materials Processing Technology. 2008; 198(1-3):48-53. http://dx.doi. org/10.1016/j.jmatprotec.2007.06.051.

16. Perig AV, Laptev AM, Golodenko NN, Erfort YA and Bondarenko EA. Equal channel angular extrusion of soft solids. Materials 
Science and Engineering A. 2010; 527(16-17):3769-3776. http://dx.doi.org/10.1016/j.msea.2010.03.043.

17. Perig AV, Zhbankov IG, Matveyev IA and Palamarchuk VA. Shape effect of angular die external wall on strain unevenness during equal channel angular extrusion. Materials and Manufacturing Processes. 2013; 28(8):916-922. http://dx.doi.org/10.1080/10 426914.2013.792417.

18. Perig AV, Zhbankov IG and Palamarchuk VA. Effect of die radii on material waste during equal channel angular extrusion. Materials and Manufacturing Processes. 2013; 28(8):910-915. http://dx.doi.org/10.1080/10426914.2013.792420.

19. Perig AV and Laptev AM. Study of ECAE mechanics by upper bound rigid block model with two degrees of freedom. Journal of the Brazilian Society of Mechanical Sciences and Engineering. 2014; 36(3):469-476. http://dx.doi.org/10.1007/ s40430-013-0121-z.

20. Perig AV and Golodenko NN. CFD Simulation of ECAE through a Multiple-Angle Die with a Movable Inlet Wall. Chemical Engineering Communications. 2014; 201(9):1221-1239. http:// dx.doi.org/10.1080/00986445.2014.894509.

21. Perig AV and Golodenko NN. CFD 2D Simulation of Viscous Flow during ECAE through a rectangular die with parallel slants. International Journal of Advanced Manufacturing Technology. 2014; 74(5-8):943-962. http://dx.doi.org/10.1007/ s00170-014-5827-2.

22. Perig AV. 2D upper bound analysis of ECAE through 20-dies for a range of channel angles. Materials Research. 2014; 17(5):1226-1237. http://dx.doi.org/10.1590/1516-1439.268114.

23. Perig AV, Tarasov AF, Zhbankov IG and Romanko SN. Effect of 20-punch shape on material waste during ECAE through a 20-die. Materials and Manufacturing Processes. 2015; 30(2):222-231. http://dx.doi.org/10.1080/10426914.2013.83 2299 .

24. Reihanian M, Ebrahimi R and Moshksar MM. Upper-bound analysis of equal channel angular extrusion using linear and rotational velocity fields. Materials \& Design. 2009; 30(1):2834. http://dx.doi.org/10.1016/j.matdes.2008.04.059.

25. Segal VM. Materials processing by simple shear. Materials Science and Engineering A. 1995; 197(2):157-164. http:// dx.doi.org/10.1016/0921-5093(95)09705-8.
26. Segal VM. Slip line solutions, deformation mode and loading history during equal channel angular extrusion. Materials Science and Engineering A. 2003; 345(1-2):36-46. http://dx.doi. org/10.1016/S0921-5093(02)00258-7.

27. Talebanpour B and Ebrahimi R. Upper-bound analysis of dual equal channel lateral extrusion. Materials \& Design. 2009; 30(5):1484-1489. http://dx.doi.org/10.1016/j.matdes.2008.08.006.

28. Tóth, L.S., Massion, R.A., Germain, L., Baik, S.C., Suwas, S. Analysis of texture evolution in equal channel angular extrusion of copper using a new flow field. Acta Materialia. 2004; 52(7): 1885-1898. http://dx.doi.org/10.1016/j.actamat.2003.12.027.

29. Berta M and Prangnell PB. The effect of dispersoids and processing variables on grain refinement of aluminium alloys deformed by ECAE. Solid State Phenomena. 2006; 114:151158. http://dx.doi.org/10.4028/www.scientific.net/SSP.114.151.

30. Farias, F.A., Pontes, M.J.H., Cintho, O.M. Processing of a duplex stainless steel by equal channel angular extrusion. Matéria. 2010, 15(2):345-354. http://dx.doi.org/10.1590/ S1517-70762010000200036.

31. Lucas, F.L.C., Guido, V., Käfer, K.A., Bernardi, H.H., Otubo, J. ECAE processed NiTi shape memory alloy. Materials Research. 2014, 17(Suppl. 1):186-190. http://dx.doi.org/10.1590/S151614392014005000034.

32. Pürçek G. Improvement of mechanical properties for $\mathrm{Zn}-\mathrm{Al}$ alloys using equal-channel angular pressing. Journal of Materials Processing Technology. 2005; 169(2):242-248. http://dx.doi. org/10.1016/j.jmatprotec.2005.03.012.

33. Iwahashi Y, Wang J, Horita Z, Nemoto M and Langdon TG. Principle of equal-channel angular pressing for the processing of ultra-fine grained materials. Scripta Materialia. 1996; 35(2):143146. http://dx.doi.org/10.1016/1359-6462(96)00107-8.

34. Johnson W and Kudo H. The mechanics of metal extrusion. Manchester University Press; 1962.

35. Kudo H. Some analytical and experimental studies of axisymmetric cold forging and extrusion - I. International Journal of Mechanical Sciences. 1960; 2(1-2):102-127. http://dx.doi. org/10.1016/0020-7403(60)90016-3. 